\title{
Genetic and epigenetic characterization of hypodiploid acute lymphoblastic leukemia
}

\author{
Setareh Safavi ${ }^{1}$, Linda Olsson ${ }^{1,2}$, Andrea Biloglav ${ }^{1}$, Srinivas Veerla ${ }^{3}$, Molly \\ Blendberg ${ }^{1}$, Johnbosco Tayebwa ${ }^{1}$, Mikael Behrendtz ${ }^{4}$, Anders Castor ${ }^{5}$, Markus \\ Hansson $^{6}$, Bertil Johansson ${ }^{1,2}$, Kajsa Paulsson ${ }^{1}$ \\ ${ }^{1}$ Division of Clinical Genetics, Department of Laboratory Medicine, Lund University, Lund, Sweden \\ ${ }^{2}$ Department of Clinical Genetics, University and Regional Laboratories, Region Skåne, Lund, Sweden \\ ${ }^{3}$ Division of Oncology and Pathology, Department of Clinical Sciences Lund, Lund University, Lund, Sweden \\ ${ }^{4}$ Department of Pediatrics, Linköping University Hospital, Linköping, Sweden \\ ${ }^{5}$ Department of Pediatrics, Skåne University Hospital, Lund University, Lund, Sweden \\ ${ }^{6}$ Division of Hematology, Skåne University Hospital, Lund University, Lund, Sweden \\ Correspondence to: \\ Setareh Safavi, e-mail: setareh.safavi@med.lu.se \\ Kajsa Paulsson, e-mail: kajsa.paulsson@med.lu.se \\ Keywords: acute lymphoblastic leukemia, hypodiploidy, next generation sequencing, chromosomal instability \\ Received: August 26, $2015 \quad$ Accepted: October 17, $2015 \quad$ Published: October 30, 2015
}

\section{ABSTRACT}

Purpose: To investigate the genetic and epigenetic landscape of hypodiploid ( $<45$ chromosomes) acute lymphoblastic leukemia (ALL).

Methods: Single nucleotide polymorphism array, whole exome sequencing, RNA sequencing, and methylation array analyses were performed on eleven hypodiploid ALL cases.

Results: In line with previous studies, mutations in IKZF3 and FLT3 were detected in near-haploid (25-30 chromosomes) cases. Low hypodiploidy (31-39 chromosomes) was associated with somatic TP53 mutations. Notably, mutations of this gene were also found in $3 / 3$ high hypodiploid (40-44 chromosomes) cases, suggesting that the mutational patterns are similar in low hypodiploid and high hypodiploid ALL. The high hypodiploid ALLs frequently displayed substantial cell-to-cell variability in chromosomal content, indicative of chromosomal instability; a rare phenomenon in ALL. Gene expression analysis showed that genes on heterodisomic chromosomes were more highly expressed in hypodiploid cases. Cases clustered according to hypodiploid subtype in the unsupervised methylation analyses, but there was no association between chromosomal copy number and methylation levels. A comparison between samples obtained at diagnosis and relapse showed that the relapse did not arise from the major diagnostic clone in $3 / 4$ cases.

Conclusion: Taken together, our data support the conclusion that near-haploid and low hypodiploid ALL are different with regard to mutational profiles and also suggest that ALL cases with high hypodiploidy may harbor chromosomal instability.

\section{INTRODUCTION}

Hypodiploidy ( $<46$ chromosomes) is found in $5-8 \%$ of acute lymphoblastic leukemia (ALL). This karyotypic feature can be further subdivided into a modal chromosome number of 45 , high hypodiploidy (HoH; 40-44 chromosomes), low hypodiploidy (HoL; 31-39 chromosomes), and near-haploidy (NH; 25-30 chromosomes) [1-5]. The majority of hypodiploid cases harbor 45 chromosomes, whereas $\mathrm{NH}, \mathrm{HoL}$, and $\mathrm{HoH}$ 
are rare, combined comprising less than $1 \%$ of $\mathrm{BCP}$ ALL $[1,2]$. Near-haploid ALL is primarily diagnosed in children and adolescents, and is associated with white blood cell (WBC) counts of $<50 \times 10^{9} / 1$ and a sex ratio close to 1[1-3]. BCP ALL with HoL, on the other hand, occurs at all ages [2], but in line with $\mathrm{NH}$, it is equally common in males and females and the WBC counts are generally $<50 \times 10^{9} / 1[1,4]$. In childhood ALL, both $\mathrm{NH}$ and $\mathrm{HoL}$ are associated with a dismal prognosis, with a 3-year event-free survival rate of $30 \%$; adult patients with HoL also have extremely poor overall survival rates of only $20-30 \%$ [1, 5-8]. The few studies specifically focusing on the rare $\mathrm{HoH}$ group have identified such cases in both childhood and adult BCP ALL [1, 3, 5, 9]. Nachman et al [5] reported that modal chromosome numbers of 40-43 were associated with a poor prognosis in childhood ALL, but their study only included eight cases.
Genetically, NH displays a nonrandom retention of chromosomes X/Y, 14, 18, and 21 [1, 3, 9-12]. A clone constituting a duplication of the stemline is frequently seen and may be mistaken for a high hyperdiploid ALL, a subgroup associated with a favorable outcome $[1,10$, $13,14]$. Recurrent microdeletions targeting $C D K N 2 A$ / $C D N K 2 B(22-50 \%)$ have been identified in NH ALL $[12,15]$ and Holmfeldt et al [15] showed that this subtype frequently also harbors mutations and deletions targeting NF1 (44\%), IKZF3 (13\%), and PAG1 (10\%) (Figure 1). The latter study also revealed deletions of the histone gene cluster at 6p22 (19\%) and mutations of histone modifier genes. The most common target was $C R E B B P$ - deletions and sequence mutations of this gene were found in $32 \%$ of $\mathrm{NH}$ cases. Alterations activating the RTK and RAS signaling pathways, including $N R A S, K R A S$, $M A P K 1, F L T 3$, and PTPN11, are also frequent (70\%) [15] (Figure 1). No recurrent fusion gene has been described.

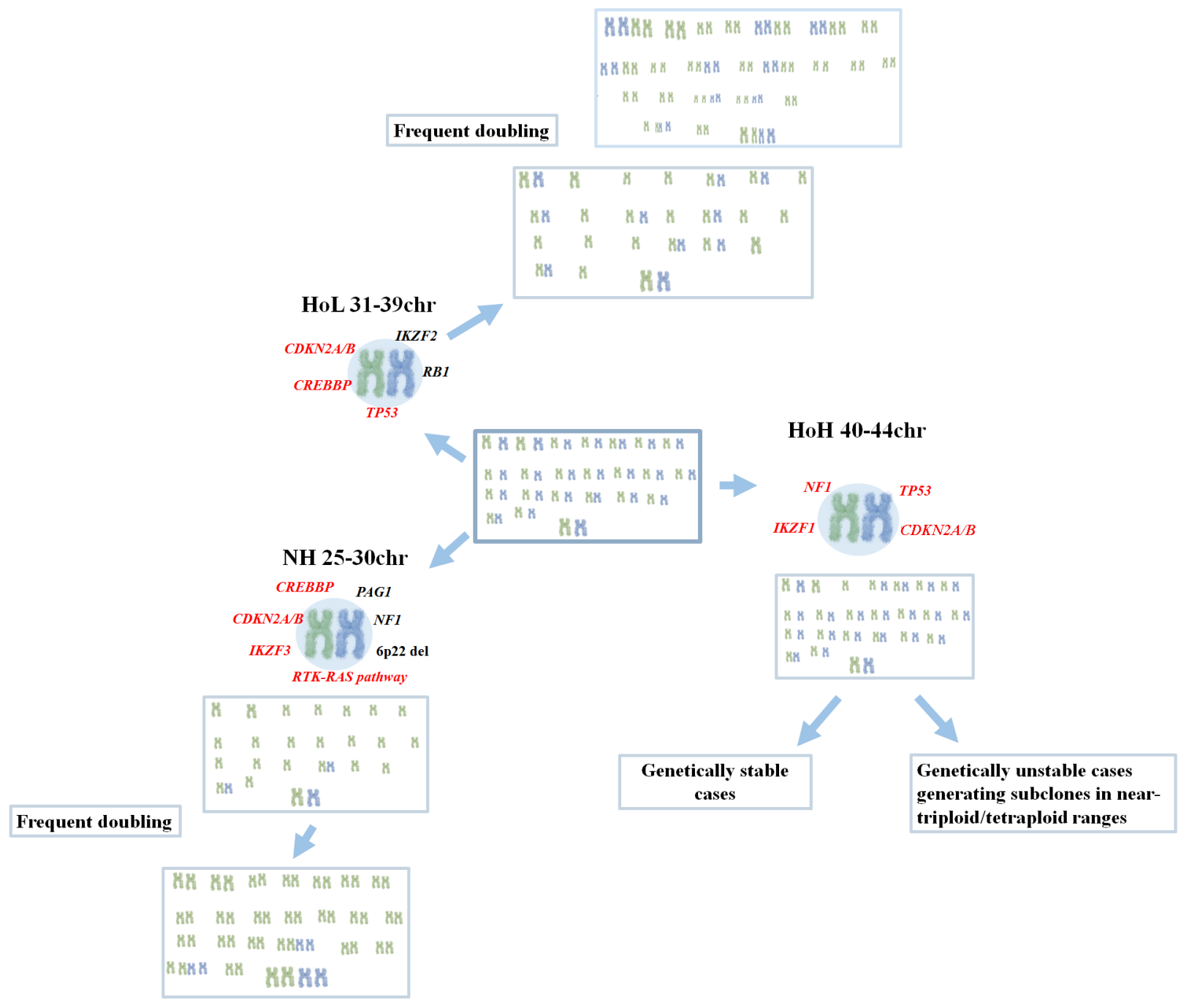

Figure 1: Summary of the genomic landscape of hypodiploid acute lymphoblastic leukemia (ALL). Chromosomal profiles of near-haploid $(\mathrm{NH})$, low hypodiploid $(\mathrm{HoL})$ and high hypodiploid $(\mathrm{HoH})$ ALL are shown, including previously known mutational targets in black and mutational targets identified or confirmed in this investigation in red. 
With regard to $\mathrm{HoL}$ ALL, it also retains chromosomes $\mathrm{X} / \mathrm{Y}, 14,18$, and 21 . In addition, disomies $1,5,6,8,10,11$, and 19 are frequent, with disomy 1 being present in close to $100 \%$ of cases. In contrast, chromosomes $3,4,7,13,15,16$, and 17 are monosomic in the majority of cases $[1,4,12,16]$. In most instances, a second clone with a duplicated chromosome number in the near-triploid range is seen $[1,4]$. In fact, because the retained chromosomes in HoL correspond to those gained in near-triploid BCP ALL these two karyotypic groups are often considered to constitute a single entity [7]. Recently, TP53 mutations were identified in $~ 90 \%$ of pediatric and adult HoL ALL $[15,16]$ (Figure 1). In pediatric HoL, TP53 mutations were frequently (43\% of cases) detected in nonmalignant hematopoietic cells, strongly suggesting that TP53 mutations in childhood HoL can be constitutional and that pediatric HoL BCP ALL hence may be a manifestation of Li-Fraumeni syndrome [15]. Adult cases, on the other hand, generally appear to have somatic TP53 mutations [15, 16]. Also IKZF2 (53\%), RB1 (41\%), and CDKN2A/CDKN2B (24\%) mutations/deletions are prevalent in HoL ALL [15] (Figure 1).

As to HoH, Harrison et al [1] reported that such BCP ALL cases are genetically similar to those with 45 chromosomes, based on the frequent presence of dicentric chromosomes, but their patient cohort comprised only five cases, all of which had 44 chromosomes. In cases with 40-43 chromosomes, available data, albeit scarce, suggest that structural aberrations are common $[3,5]$. Doubling of the hypodiploid clone has only been reported in a few cases [3]. To the best of our knowledge, no study has been reported to date where next-generation sequencing has been used to investigate this subgroup.

In the present study, we performed whole exome sequencing (WES), RNA sequencing (RNA seq), and methylation array analyses of $\mathrm{NH}, \mathrm{HoL}$, and $\mathrm{HoH}$ ALL in order to investigate further the genomic and epigenomic background of hypodiploid ALL.

\section{RESULTS}

\section{Copy number, microdeletions, and subclonality detected by SNP array analysis}

Of the eleven hypodiploid cases included in the study, four were NH, 3 were HoL, and 1 case was $\mathrm{HoH}$. The remaining three cases had G-banding karyotypes showing 79-93 chromosomes. However, data from SNP array analyses showed that many chromosomes harbored complete loss of heterozygosity $(\mathrm{LOH})$, similar to that seen in doubled cases of NH and HoL. We thus deem it likely that they originated via doubling of a hypodiploid clone. However, we cannot determine definitely whether this original clone had a modal number in the $\mathrm{HoL}$ or $\mathrm{HoH}$ range, since these cases also appear to have chromosomal instability (see below for further information). To account for this uncertainty, we classify these cases as " $\mathrm{HoL} / \mathrm{HoH}$ " below.

Two HoL cases (\#6 and 7) had homozygous loss of part or all of $C R E B B P$, which had been missed in the previous analysis of SNP array data. For the $\mathrm{HoL} / \mathrm{HoH}$ and the $\mathrm{HoH}$ case, complete $\mathrm{LOH}$ was seen for chromosomes 4, 5, and 16 in 4/4 cases. All HoL/HoH cases (\#8, 9 and 10) had allelic ratios indicative of variable copy number, i.e., subclonality, for whole chromosomes. The median number of microdeletions was 1.75 per case in the $\mathrm{HoH}$ and $\mathrm{HoL} /$ $\mathrm{HoH}$ group. Two of the three $\mathrm{HoL} / \mathrm{HoH}$ cases harbored $C D K N 2 A / B$ deletions; in one of these, the deletion was also seen at relapse (Supplementary Table S1).

\section{WES results confirms the subtype-specific mutations in hypodiploid ALL}

A total of 399 non-synonymous mutations predicted to be deleterious were identified by WES (Supplementary Table S3), of which 24 were in genes that have been previously reported to be mutated in $\mathrm{NH}$ and HoL ALL [15]. Recurrently mutated genes included TP53 (55\%), GPR98 (22\%), and TTN (22\%). The WES analysis also detected mutations in genes known to be mutated in NH ALL, such as IKZF3 (one relapse sample) and FLT3 (1/3 cases). In HoL, TP53 alterations were found in both cases analyzed (100\%); the MAFs of these mutations suggested that they were acquired rather than constitutional. In the three $\mathrm{HoL} / \mathrm{HoH}$ cases analyzed, NFI mutations were identified in matching diagnostic and relapse material in one case, IKZFI alterations in one case (also at relapse), and TP53 mutations in all three cases, including the relapse sample in case 9 (Supplementary Table S3).

\section{Clonal relationship between diagnosis and relapse samples}

In all three cases for which paired diagnostic and relapse samples were available, the relapse samples harbored more mutations (Table 2). The clonal relationship between paired diagnostic and relapse samples could be successfully compared by SNP array analysis in cases 2, 4, 5 , and 9 and by WES in cases 2, 4, and 9 (Table 2). Cases 5 and 9 displayed differences in copy number alterations between diagnosis and relapse, whereas cases 2, 4, and 9 displayed different mutations in both diagnostic and relapse samples (Table 2).

Mutated genes unique for a diagnostic or relapse sample included $P A R D 3 B$ at diagnosis and TAOK2 and $C R E B B P$ at relapse in case 2. In case 4, FLT3 and $P A X 9$ mutations were seen at relapse only and in case 9, $P I K 3 C 2 B$ was mutated only at relapse. 
Table 1: Basic clinical and genetic features of the 11 hypodiploid BCP ALL cases

\begin{tabular}{|c|c|c|c|c|c|c|c|c|}
\hline \multirow{2}{*}{$\begin{array}{l}\text { Case } \\
\text { No. }\end{array}$} & \multirow[t]{2}{*}{ Sex/age } & \multirow{2}{*}{$\begin{array}{l}\text { Genetic } \\
\text { subtype }\end{array}$} & \multirow[t]{2}{*}{ Karyotype } & \multirow{2}{*}{$\begin{array}{l}\text { Whole chromosome } \\
\text { changes detected by } \\
\text { SNP array analysis* }\end{array}$} & \multicolumn{4}{|c|}{ Analyses performed } \\
\hline & & & & & WES & RNA seq & Meth array & FISH \\
\hline $1 \mathrm{Dx}$ & $\mathrm{F} / 1$ & $\mathrm{NH}$ & $\begin{array}{c}25, \mathrm{X},+\mathrm{X},+21 / 50 \\
\text { idemx } 2\end{array}$ & $25, \mathrm{X},+\mathrm{X},+21$ & Yes & No & Yes & No \\
\hline $2 \mathrm{Dx}$ & $\mathrm{F} / 2$ & $\mathrm{NH}$ & Failure & $\begin{array}{c}27, \mathrm{X},+\mathrm{X},+14,+18 \\
+21\end{array}$ & Yes & No & Yes & No \\
\hline $2 \mathrm{R}$ & $\mathrm{F} / 4$ & & Failure & $\begin{array}{c}27, \mathrm{X},+\mathrm{X},+14,+18 \\
+21\end{array}$ & Yes & No & Yes & No \\
\hline $3 R$ & $\mathrm{M} / 4$ & $\mathrm{NH}$ & $\begin{array}{c}29, \mathrm{X},+\mathrm{X},+\mathrm{Y},+\mathrm{Y} \\
+14,+18,+21 / 58 \\
\quad \text { idemx } 2\end{array}$ & $\begin{array}{c}29, \mathrm{X},+\mathrm{X},+\mathrm{Y},+\mathrm{Y} \\
\quad+14,+18,+21\end{array}$ & Yes & No & Yes & No \\
\hline $4 \mathrm{Dx}$ & $\mathrm{F} / 12$ & $\mathrm{NH}$ & $\begin{array}{c}51-52, \mathrm{XX},+\mathrm{X},+21 \\
\text { inc }\end{array}$ & $26, X,+X,+14,+21$ & Yes & Yes & Yes & No \\
\hline $4 \mathrm{R}$ & $\mathrm{F} / 15$ & & Normal & $26, \mathrm{X},+\mathrm{X},+14,+21$ & Yes & Yes & Yes & No \\
\hline $5 \mathrm{Dx}$ & $\mathrm{M} / 48$ & HoL & Normal & $\begin{array}{c}32, \mathrm{X},+1,+5,+6, \\
+8,+10,+14,+19, \\
+21,+22\end{array}$ & Yes & No & Yes & Yes \\
\hline $5 \mathrm{R}$ & $\mathrm{M} / 49$ & & Normal & $\begin{array}{c}32, \mathrm{X},+1,+5,+6, \\
+8,+10,+14,+19, \\
+21,+22\end{array}$ & No & Yes & No & Yes \\
\hline $6 \mathrm{Dx}$ & $\mathrm{F} / 56$ & HoL & Normal & $\begin{array}{l}34, X,+X,+1,+2, \\
+6,+10,+11,+12, \\
+14,+18,+21,+22\end{array}$ & Yes & No & Yes & No \\
\hline 7Dx & $\mathrm{M} / 62$ & HoL & $\begin{array}{c}33, \mathrm{X},+\mathrm{Y},+1,+6, \\
+10,+11,+14,+18 \\
+19,+21,+22, \\
\text { inc/61-65, idemx2, } \\
\text { inc }\end{array}$ & $\begin{array}{l}33, \mathrm{X},+\mathrm{Y},+1,+5 \\
+6,+10,+11,+18 \\
\quad+19,+21,+22\end{array}$ & No & Yes & No & No \\
\hline $8 \mathrm{Dx}$ & $\mathrm{F} / 32$ & $\begin{array}{l}\text { HoL/ } \\
\mathrm{HoH}\end{array}$ & $\begin{array}{c}84, \mathrm{XXXX},-2,-3,-4 \\
-5,+6,-7,-8,-9,+10 \\
+14,-15,-15,-16 \\
-17,-17,+18,-19 \\
+21\end{array}$ & $\begin{array}{l}\text { Complete LOH for } \\
\text { chr3, chr4, chr5, } \\
\text { chr7, chr9, chr13, } \\
\text { chr15, chr16, chr17, } \\
\text { chr20 }\end{array}$ & Yes & No & Yes & Yes \\
\hline 9Dx & $\mathrm{M} / 52$ & $\begin{array}{l}\mathrm{HoL} / \\
\mathrm{HoH}\end{array}$ & Failure & $\begin{array}{l}\text { Varying copy number } \\
\text { for all chromosomes }\end{array}$ & Yes & No & Yes & No \\
\hline $9 \mathrm{R}$ & $\mathrm{M} / 52$ & & $\begin{array}{c}\text { 84-93, XX, +X, } \\
\text {-Y, -Y, +add(1) } \\
\text { (p36), -3, -4, +6, } \\
+6,+? \operatorname{der}(6 ; 15) \\
\text { (p10;q10), -7, } \\
\text { der(11) } \\
\text { t(11;11)(p11;q13), } \\
-14,-15,-15 \\
-15,-16,-18 \text { or } \\
+18 ? ?,+21,+21,-22 \\
\quad+6 \text { mar }\end{array}$ & $\begin{array}{l}\text { Varying copy number } \\
\text { for all chromosomes }\end{array}$ & Yes & No & Yes & Yes \\
\hline
\end{tabular}

(Continued) 


\begin{tabular}{|c|c|c|c|c|c|c|c|c|}
\hline \multirow{2}{*}{$\begin{array}{l}\text { Case } \\
\text { No. }\end{array}$} & \multirow[t]{2}{*}{ Sex/age } & \multirow{2}{*}{$\begin{array}{l}\text { Genetic } \\
\text { subtype }\end{array}$} & \multirow[t]{2}{*}{ Karyotype } & \multirow{2}{*}{$\begin{array}{l}\text { Whole chromosome } \\
\text { changes detected by } \\
\text { SNP array analysis* }\end{array}$} & \multicolumn{4}{|c|}{ Analyses performed } \\
\hline & & & & & WES & RNA seq & Meth array & FISH \\
\hline 10Dx & $\mathrm{F} / 70$ & $\begin{array}{l}\mathrm{HoL} / \\
\mathrm{HoH}\end{array}$ & $\begin{array}{c}79-80, \mathrm{XXX},+1,+2 \\
-4,-8,-9,+11,+12 \\
-16, \text { inc }\end{array}$ & $\begin{array}{l}\text { Complete LOH for } \\
\text { chr3, chr4, chr7, } \\
\text { chr8, chr9, chr13, } \\
\text { chr14, chr15, chr16, } \\
\text { chr17, chr20, chr22 }\end{array}$ & Yes & No & Yes & Yes \\
\hline 11Dx & $\mathrm{F} / 75$ & $\mathrm{HoH}$ & $\begin{array}{c}40, X X, \operatorname{add}(1)(\mathrm{q} 31), \\
-3,-4,-5, \operatorname{add}(7) \\
(\mathrm{q} 11),-9,-11,-13, \\
-16,-17,-17,-18, \\
+4 \mathrm{mar}\end{array}$ & $\begin{array}{l}\text { Complete LOH for } \\
\text { chr4, chr5, chr16 }\end{array}$ & No & No & No & Yes \\
\hline
\end{tabular}

BCP ALL - B-cell precursor acute lymphoblastic leukemia, Dx - diagnosis, F - female, FISH - fluorescence in situ hybridization, HoH - high hypodiploid (40-44 chromosomes), HoL - low hypodiploid (31-39 chromosomes), LOH - loss of heterozygosity, M - male, Meth - methylation, NH - near-haploid (25-30 chromosomes), R - relapse, SNP - single nucleotide polymorphism, WES - whole exome sequencing.

"Copy number changes are given in relation to the haploid level except for cases 8-11. All chromosomes that were not gained displayed complete loss of heterozygosity in cases $1-7$.

Table 2: Clonal relationship between diagnosis and relapse in hypodiploid ALL

\begin{tabular}{|c|c|c|c|c|}
\hline Case No. & Subgroup & $\begin{array}{c}\text { Genomic imbalances seen only at } \\
\text { diagnosis or relapse } \\
\text { Position (bp) }\end{array}$ & $\begin{array}{l}\text { Unique mutations } \\
\text { detected only at } \mathrm{dx} / \\
\text { relapse }\end{array}$ & $\begin{array}{c}\text { Genetic } \\
\text { relationship }\end{array}$ \\
\hline $\begin{array}{l}2 \mathrm{D} \\
2 \mathrm{R}\end{array}$ & NH & $\begin{array}{l}\text { None } \\
\text { None }\end{array}$ & $\begin{array}{c}8 \\
84\end{array}$ & Ancestral clone \\
\hline $\begin{array}{l}4 \mathrm{D} \\
4 \mathrm{R}\end{array}$ & NH & $\begin{array}{l}\text { None } \\
\text { None }\end{array}$ & $\begin{array}{c}8 \\
317\end{array}$ & Ancestral clone \\
\hline $\begin{array}{l}5 \mathrm{D} \\
5 \mathrm{R}\end{array}$ & HoL & $\begin{array}{c}\text { None } \\
\operatorname{del}(\operatorname{chr} 1: 210,984,565 \text {-qter })\end{array}$ & - & Major clone \\
\hline $\begin{array}{l}9 \mathrm{D} \\
9 \mathrm{R}\end{array}$ & $\mathrm{HoL} / \mathrm{HoH}$ & $\begin{array}{c}\text { Subclonal+1, subclonal }+12 \text {, subclonal }+21 \\
\text { Subclonal del(chr12:76, 900, 956-91, } \\
479,154)\end{array}$ & $\begin{array}{c}1 \\
12\end{array}$ & Ancestral clone \\
\hline
\end{tabular}

bp - base pair, chr - chromosome, D - diagnostic sample, del - deletion, dup - duplication, HoH - high hypodiploidy,

HoL- low hypodiploidy, NH - near-haploidy, qter - q-terminal, R - relapse sample.

\section{Geneset enrichment analysis reveals higher expression of genes on heterodisomic chromosomes in NH and HoL ALL}

The DeSeq gene expression analysis revealed two genes to be upregulated in hypodiploid cases compared with the controls, namely IGFBP2 and $P A R D 3 B$. Unsupervised principal component analysis (PCA) of $\mathrm{NH}, \mathrm{HoL}$, and control cases identified that they clustered separately (Supplementary Figure S1a). Differential expression analysis (variance 0.68 ) between $\mathrm{NH}, \mathrm{HoL}$, and control cases resulted in 76 differentially expressed probe sets. Supervised hierarchical clustering analysis on $\mathrm{NH}, \mathrm{HoL}$, and control $(\mathrm{FDR}<0.01)$ revealed 160 differentially expressed genes (Supplementary Figure S1b). GSEA showed possible enrichment of genes on chromosomes X, Y, 14, and 21 in $\mathrm{NH}$ cases and of genes on chromosomes X, Y, 1, 5, 6, 8, $10,11,18,19,21$, and 22 in HoL cases, but none of the expression differences was statistically significant. GSEA results from Holmfeldt et al [15] for HoL cases, showed enrichment of genes on chromosomes 1 ( $P$-value: 0.004, $q$-value: 0.174$), 8$ ( $P$-value: $0.009, q$-value:0.146), 10 $(P$-value: $0.004, q$-value: 0.251$), 11$ ( $P$-value: 0.032 , $q$-value: 0.128$), 21$ ( $P$-value: $0.017, q$-value: 0.149$)$, and $\mathrm{X}$ ( $P$-value: $0.021, q$-value:0.214). For the $\mathrm{NH}$ cases the analysis showed enrichment of genes on chromosomes 21 
( $P$-value: $0.009, q$-value: 0.027$)$ and $\mathrm{X}(P$-value: 0.005 , $q$-value: 0.034$)$. No fusion transcripts could be confirmed in the three samples analyzed.

\section{Methylation status confirms the divergent profiles in NH, HoL, and HoL/HoH ALL}

Unsupervised PCA of methylation array data from all hypodiploid cases, including matching relapse samples $(n=12)$, revealed that $\mathrm{NH}, \mathrm{HoL}$, and $\mathrm{HoL} / \mathrm{HoH}$ cases formed distinct clusters (variance $=0.75$ ). When restricting the analysis to commonly lost or retained chromosomes, similar clusters were formed in an unsupervised PCA (Supplementary Figure S2). To investigate whether the methylation status of genes differed between $\mathrm{NH}$, HoL, $\mathrm{HoL} / \mathrm{HoH}$, and control samples, we analyzed methylation array results in a supervised multigroup PCA. The analysis revealed 143 genes with significantly different methylation patterns in the $\mathrm{NH}, \mathrm{HoL}, \mathrm{HoL} / \mathrm{HoH}$, and control groups $(P<0.05$, FDR $<0.1)$ (Supplementary Figure S3). We performed an unsupervised multigroup analysis (variance 0.2 ) comparing the mean $\beta$ values of all $\mathrm{NH}$ and HoL diagnostic cases and controls, including an additional analysis between $\mathrm{NH}$ and $\mathrm{HoL} / \mathrm{HoH}$ at diagnosis and relapse. The analysis did not detect any significant methylation level changes between hypodiploid samples and controls. Furthermore, there were no statistically significant changes in methylation levels between diagnostic and relapse samples.

\section{FISH analysis identifies clonal heterogeneity in HoL/HoH ALL}

For the $\mathrm{HoL} / \mathrm{HoH}$ cases, the SNP array analysis results suggested subclonality of whole chromosomes. Interphase and metaphase FISH was performed to investigate chromosomal copy numbers for these cases (Supplementary Table S4), including all chromosomes in cases 8 and 10 and a subset of chromosomes in case 9 . Variable copy numbers were detected for the majority of chromosomes, including both chromosomes that showed retained heterozygosity and those that showed complete LOH (Supplementary Table S4).

\section{DISCUSSION}

Cytogenetically, three genetic subtypes of hypodiploid ALL have been delineated, namely $\mathrm{NH}$, HoL, and HoH. Recently Holmfeldt et al [15] showed that $\mathrm{NH}$ and $\mathrm{HoL}$ cases have different mutational profiles, indicating that this classification identifies true biological differences in childhood cases. In the present study, we confirm several of the subtype-specific mutations in additional hypodiploid cases (Figure 1), investigate adult cases, and add new insight into the pathogenesis of HoL/ HoH ALL.
The chromosomal patterns seen in $\mathrm{NH}$ and HoL cases agreed well with what has been previously published $[1,3,9,15]$. In line with Holmfeldt et al [15], IKZF3 and FLT3 mutations were detected in $\mathrm{NH}$ cases, $2 / 2 \mathrm{HoL}$ cases investigated by WES had TP53 mutations, and $2 / 3 \mathrm{HoL}$ cases analyzed by SNP arrays had $C D K N 2 A$ deletions. However, whereas Holmfeldt et al [15] found that alterations affecting $C R E B B P$ were restricted to $\mathrm{NH}$, $2 / 3 \mathrm{HoL}$ cases in our study had microdeletions of part of this gene. Since their study included only pediatric cases and all our HoL patients were adults, it is possible that $C R E B B P$ deletions may be pathogentically important primarily in adult HoL ALL.

The present study included 1 case of HoH ALL, a very rare subgroup that has been little investigated, and three additional possible $\mathrm{HoH}$ cases. The latter were classified as hypodiploid ALL based on the results from SNP array analysis, which showed $\mathrm{LOH}$ for a subset of the chromosomes (Table 1), similar to the pattern seen in $\mathrm{NH}$ and $\mathrm{HoL}$ cases with doubling of chromosomes. Notably, all three cases with widespread LOH harbored substantial heterogeneity in chromosomal numbers between cells, indicative of chromosomal instability (CIN) (Supplementary Table S4). The HoH case with 40 chromosomes did not have a doubled clone and did not show any evidence of CIN, although many microdeletions were detectable by SNP array analysis (Supplementary Table S1). We have found SNP array data from two additional $\mathrm{HoH}$ cases, both with 43 chromosomes, in the literature [15]; none of these harbored evidence of clonal heterogeneity in chromosomal numbers. Thus, some cases with modal numbers in the upper $\mathrm{HoL}$ and $\mathrm{HoH}$ range may be characterized by chromosomal doubling followed by CIN. As regards specific gene targets, $C D K N 2 A$ deletions have been identified in the two $\mathrm{HoH}$ cases investigated by SNP array analysis [15] and in two out of three $\mathrm{HoL} / \mathrm{HoH}$ cases investigated in our study. To the best of our knowledge, no previous study has used WES to investigate $\mathrm{HoH}$ ALL, but targeted gene sequencing has been reported for three cases; all of those had TP53 mutation $[15,16]$. In line with this, all our three HoL/ $\mathrm{HoH}$ also had such mutations. Based on this, we suggest that HoH BCP ALL may be genetically similar to HoL ALL and should perhaps be classified as such.

The genomic landscape of hypodiploid ALL is characterized by aneuploidy and mutations, with few microdeletions and structural rearrangements. This is similar to high hyperdiploid (51-67 chromosomes) childhood ALL [26], which is associated with massive chromosomal gains instead of losses. Thus, the pathogenetic mechanisms may be similar in these two disorders, although the clinical outcomes differ substantially. In both ALL subtypes, aneuploidy seems to be the main driver event, but its functional consequences are still poorly understood, although dosage effects are 
likely to be important. The fact that different tumors displaying massive hypodiploidy retain different chromosomes in a heterodisomic state supports this scenario [27].

In inflammatory leiomyosarcoma with $\mathrm{NH}$, it has been shown that the loss of chromosomes leads to a general decrease in expression from genes on these chromosomes. ${ }^{28}$ In the present study, RNA-seq data were only available from 3 cases, hampering analyses of gene expression on a global scale. Therefore, we also performed a separate GSEA using data from Holmfeldt et al [15]. These analyses showed that genes on the most commonly retained chromosomes in $\mathrm{NH}$ and $\mathrm{HoL}$ cases were enriched in these subtypes compared with neardiploid/diploid ALL, indicating that the aneuploidy is associated with specific gene dosage effects. Another possibility is that the monosomic chromosomes display a different methylation pattern, which could also affect gene expression. However, we could not detect any general differences in methylation between chromosomes present in one or two copies in NH and HoL. In line with this, unsupervised methylation analysis resulted in clusters for $\mathrm{NH}, \mathrm{HoL}$, and $\mathrm{HoL} / \mathrm{HoH}$ that remained when the analyses were restricted to genes on the retained chromosomes or genes on the lost chromosomes, indicating the differences in methylation levels were not due to chromosomal copy number (Supplementary figure S2). It should be noted that the methylation arrays used in the present investigation primarily includes CpGs in promotors, and it is hence possible the monosomic chromosomes exhibit different methylation patterns outside of these regions. Paired diagnostic and relapse samples could be successfully investigated for four cases - two $\mathrm{NH}$, one HoL, and one $\mathrm{HoL} / \mathrm{HoH}$ (Table 2). These analyses showed copy number changes and/or mutations that were unique for the diagnostic or relapse sample, respectively, in cases 2,4 , and 9 , indicating that the relapse did not arise from the major diagnostic clone but rather from an ancestral clone. In case 5, unique copy number changes were seen only in the relapse sample, compatible with a scenario where the relapse developed from the major diagnostic clone; however, since no mutation analysis was done in this case, the clonal relationship cannot be definitively determined. Notably, all relapse samples showed many more mutations than the corresponding diagnostic sample (Table 2), indicating rapid selection and possibly an increased mutation rate, both of which could be treatment-related.

Taken together, our results confirm the mutational differences recently described between $\mathrm{NH}$ and $\mathrm{HoL}$ ALL, and suggest that adult $\mathrm{HoL}$ is genetically similar to childhood cases. It is notable that the current WHO classification groups all hypodiploid ALL together (WHO classification of tumours of haematopoietic and lymphoid tissues)[28]. The data from Holmfeldt et al [15], Mülbacher et al [16], and this study suggest that at least
$\mathrm{NH}$ and $\mathrm{HoL}$ should be considered separate entities, with the latter also being defined by TP53 mutations in addition to the hypodiploidy.

We also provide the first complete genetic characterization of $\mathrm{HoH}$ ALL. Although our data are limited, the fact that TP53 mutations have been found in all $\mathrm{HoL} / \mathrm{HoH}$ and $\mathrm{HoH}$ investigated so far suggests that the pathogenetic mechanism may be similar to the one operating in HoL. However, we also detected evidence for $\mathrm{CIN}$ in $\mathrm{HoL} / \mathrm{HoH}$; a rare phenomenon in ALL [29]. The doubled clone of HoL ALL is sometimes not an exact duplicate of the hypodiploid clone, indicating that additional copy number changes of whole chromosomes may take place in these cases, but chromosomal gains or losses restricted to a few chromosomes are not necessarily associated with CIN. Thus, to the best of our knowledge, this is the first description of possible CIN in hypodiploid ALL. Further studies will be needed to determine whether $\mathrm{CIN}$ is generally present in ALL originating as a clone with modal numbers in the upper $\mathrm{HoL} / \mathrm{HoH}$ range.

\section{MATERIALS AND METHODS}

\section{Patients}

The study comprised a total of 11 cases with hypodiploid BCP ALL, diagnosed between 1995 and 2012. These included four cases of NH, 3 cases of HoL, 1 case of $\mathrm{HoH}$, and three cases classified as $\mathrm{HoL} / \mathrm{HoH}$, as described in the Results section. Of the patients, four were children and seven were adults (range 1-75 years); the cytogenetic and clinical features are summarized in Table 1. All cases were cytogenetically analyzed as part of clinical routine at the Department of Clinical Genetics, University and Regional Laboratories, Region Skåne, Lund, Sweden. SNP array data have been previously published [12, $17,18]$. In total, such data were available for diagnosis and relapse samples from 10 and 5 cases, respectively (Table 1; Supplementary Table S1). Remission material was available for case 3 . The investigation was approved by the Research Ethics Committee of Lund University, and informed consent was provided according to the Declaration of Helsinki.

\section{Whole exome sequencing}

WES was performed on nine diagnostic samples, three paired relapse samples, and one additional relapse sample for which diagnostic material was unavailable (Table 1). A remission sample was available only in case 3. Libraries were constructed using the SureSelectXT2 Human All Exon V4 kit (Agilent Technologies, Santa Clara, CA) and cases were subjected to paired-end next generation sequencing (NGS) with an Illumina Hiseq2000 (Illumina, San Diego, CA) by BGI Tech Solutions (Hong 
Kong). SNP calling was performed using SOAPsnp [19]. For all cases except case 3, the results were further filtered by removing synonymous mutations, neutral mutations (Condel) [20], and variants detected in the 1000 Genomes project (1000g2012apr) and/or the Single Nucleotide Polymorphism Database (dbSNP129). In addition, BAM files were analyzed using the StrandNGS software (Agilent Technologies). Variants in TP53 were kept if they had been reported as somatic in the COSMIC database (http://cancer. sanger.ac.uk/cancergenome/projects/cosmic/), regardless of the above filtering. In cases $1,4,5$, and 6 , the samples contained a sufficient amount of normal cells to enable a strategy in which where mutations were classified as acquired or constitutional based on their mutant allele fractions (MAFs). In short, if the fraction of leukemic cells in the sample is considered to be $\mathrm{x}$ and the fraction of normal cells is $1-x$, the MAFs for acquired mutations in monosomic chromosomes is predicted to be $\mathrm{x} /(\mathrm{x}+2(1-\mathrm{x}))$, the MAFs for constitutional variants in the lost homologue $(1-x) /(x+2(1-x))$, and the MAFs for constitutional variants in the retained homologue $(1 x+(1-x) /(x+2(1-x))$. Comparisons between diagnostic and relapse samples and between relapse and remission sample in case 3 was done for three cases using MuTect and Indelocator [21].

\section{RNA sequencing}

RNA seq was performed on Illumina Hiseq2000 by BGI Tech Solutions on three cases: one NH, including material from a paired relapse sample, and $2 \mathrm{HoL}$ (Table 1). Five pediatric and adult ALL samples with normal karyotypes were included as controls. Prior to sequencing, the Truseq RNA sample Prep kit (Illumina) was used, for library preparation. Reads were mapped to reference sequences using SOAPaligner/SOAP2 [19], with a read length of $100 \mathrm{bp}$ and $100 \mathrm{x}$ coverage. To identify candidate fusion transcripts from the sequence data, analyses were performed on FASTQ files applying the ChimeraScan (version 0.4.5), SOAPfuse (version 1.26), and TopHat (version 2.0.7) software. The GRCh37/hg19 build was used as the human reference genome. For gene expression profile analysis, the $\mathrm{R}$ package DESeq (version 2.0), using a false discovery rate $(\mathrm{FDR}) \leq 0.01$ and a fold change $>2$, was applied to test for differential gene expression [22]. In addition, statistical analysis and visualization of the RNA sequencing data were performed using Qlucore Omics Explorer 3.1 (Qlucore, Lund, Sweden). Probe sets below a FDR cut-off of 0.01 were considered differentially expressed.

\section{Methylation array analysis}

Methylation array analysis was performed on a total of 9 cases $(4 \mathrm{NH}, 2 \mathrm{HoL}$, and $3 \mathrm{HoL} / \mathrm{HoH}$; Table 1) using the HumanMethylation450 Analysis BeadChip and processed according to the Illumina Infinium $450 \mathrm{~K}$ Methylation array assay procedure (Illumina). The NH cell line Nalm16 and three controls - one pediatric and two adult ALL cases with normal karyotype - were included in the analysis. The data were normalized according to standard procedures using $\mathrm{R}$ (version 2.14.0) with Bioconductor packages (version 2.9) [23] and then analyzed using Qlucore Omics Explorer 3.1 (Qlucore). Probe sets below an FDR cut-off of 0.1 were considered differentially methylated. Gene set enrichment analysis (GSEA) [24, 25] was done in Qlucore Omics Explorer 3.1 with gene sets corresponding to whole chromosomes, comparing $\mathrm{NH}$ and $\mathrm{HoL}$ cases with BCP ALLs with a normal karyotype. Furthermore, GSEA was performed on expression data generated by Holmfeldt et al [15] (GSE27237_RAW; Gene Expression Omnibus database, http://www.ncbi.nlm.nih.gov/geo/), comparing NH cases and controls (ETV6/RUNX1-positive ALL) and HoL and controls (ETV6/RUNX1-positive ALL).

\section{Fluorescence in situ hybridization (FISH)}

Interphase and metaphase FISH analyses were performed in order to investigate chromosomal copy numbers for cases 8D, 9R, and 10D. FISH was carried out according to standard methods using centromere-specific probes or locus specific probes (Abbott Scandinavia, Stockholm, Sweden). For interphase FISH, a minimum of 200 nuclei were analyzed for each probe.

\section{RT-PCR}

To validate possible fusion genes detected by the RNA seq, RT-PCR was performed according to standard methods. Primers specific for PIM3, SCO2, N4BP2L1, HMGB1, TPM4, KLF2, ZEB2, CXCR4, B2M, and KLC1 were designed to detect possible fusion transcripts (Supplementary Table S2). Products were amplified using an initial denaturation for 2 minutes at $94^{\circ} \mathrm{C}$, followed by 30 cycles of 30 seconds at $94^{\circ} \mathrm{C}, 30$ seconds at $58^{\circ} \mathrm{C}$, and 3 minutes at $72^{\circ} \mathrm{C}$, and a final extension for 3 minutes at $72^{\circ} \mathrm{C}$.

\section{ACKNOWLEDGMENTS AND FUNDING}

SNP array analysis was performed by SCIBLU Genomics services, Lund, Sweden.

This study was supported by grants from the Swedish Cancer Society, the Swedish Childhood Cancer Foundation, Ellen Bachrach's foundation and the Swedish Research Council.

\section{CONFLICTS OF INTEREST}

The authors declare no competing financial interests. 


\section{REFERENCES}

1. Harrison CJ, Moorman AV, Broadfield ZJ, Cheung KL, Harris RL, Reza Jalali G, Robinson HM, Barber KE, Richards SM, Mitchell CD, Eden TO, Hann IM, Hil FG, et al. Three distinct subgroups of hypodiploidy in acute lymphoblastic leukaemia. British Journal of Haematology. 2004; 125:552-559.

2. Mitelman F, Johansson B, Mertens F. Mitelman Database of Chromosome Aberrations and Gene Fusions in Cancer. http://cgap.nci.nih.gov/Chromosomes/Mitelman.

3. Pui CH, Carroll AJ, Raimondi SC, Land VJ, Crist WM, Shuster JJ, Williams DL, Pullen DJ, Borowitz MJ, Behm FG. Clinical presentation, karyotypic characterization, and treatment outcome of childhood acute lymphoblastic leukemia with a near-haploid or hypodiploid less than 45 line. Blood. 1990; 75:1170-1177.

4. Charrin C, Thomas X, Ffrench M, Le QH, Andrieux J, Mozziconacci MJ, Laï JL, Bilhou -Nabera C, Michaux L, Bernheim A, Bastard C, Mossafa H, Perot C, et al. A report from the LALA-94 and LALA-SA groups on hypodiploidy with 30 to 39 chromosomes and near-triploidy: 2 possible expressions of a sole entity conferring poor prognosis in adult acute lymphoblastic leukemia (ALL). Blood. 2004; 104:2444-2451.

5. Nachman JB, Heerema NA, Sather H, Camitta B, Forestier E, Harrison CJ, Dastugue N, Schrappe M, Pui CH, Basso G, Silverman LB, Janka -Schaub GE. Outcome of treatment in children with hypodiploid acute lymphoblastic leukemia. Blood. 2007; 110:1112-1115.

6. Raimondi SC, Zhou Y, Mathew S, Shurtleff SA, Sandlund JT, Rivera GK, Behm FG, Pui CH. Reassessment of the prognostic significance of hypodiploidy in pediatric patients with acute lymphoblastic leukemia. Cancer. 2003; 98:2715-2722.

7. Moorman AV, Harrison CJ, Buck GAN, Richards SM, Secker-Walker LM, Martineau M, Vance GH, Cherry AM, Higgins RR, Fielding AK, Foroni L, Paietta E, Tallman MS, et al. Karyotype is an independent prognostic factor in adult acute lymphoblastic leukemia (ALL): analysis of cytogenetic data from patients treated on the Medical Research Council (MRC) UKALLXII/Eastern Cooperative Oncology Group (ECOG) 2993 trial. Blood. 2007; 109:3189-3197.

8. Forestier E, Johansson B, Gustafsson G, Borgstrom G, Kerndrup G, Johannsson J, Heim S. Prognostic impact of karyotypic findings in childhood acute lymphoblastic leukaemia: a Nordic series comparing two treatment periods. British Journal of Haematology. 2000; 110:147-153.

9. Heerema NA, Nachman JB, Sather HN, Sensel MG, Lee MK, Hutchinson R, Lange BJ, Steinherz PG, Bostrom B, Gaynon PS, Uckun F. Hypodiploidy with less than 45 chromosomes confers adverse risk in childhood acute lymphoblastic leukemia: a report from the children's cancer group. Blood. 1999; 94:4036-4045.
10. Brodeur GM, Williams DL, Look AT, Bowman WP, Kalwinsky DK. Near-haploid acute lymphoblastic leukemia: a unique subgroup with a poor prognosis?. Blood. 1981; 58:14-19.

11. Gibbons B, MacCallum P, Watts E, Rohatiner AZ, Webb D, Katz FE, Secker-Walker LM, Temperley IJ, Harrison CJ, Campbell RH. Near haploid acute lymphoblastic leukemia: seven new cases and a review of the literature. Leukemia. 1991; 5:738-743.

12. Safavi S, Forestier E, Golovleva I, Barbany G, Nord KH, Moorman AV, Harrison CJ, Johansson B, Paulsson K. Loss of chromosomes is the primary event in near-haploid and low-hypodiploid acute lymphoblastic leukemia. Leukemia. 2013; 27:248-250.

13. Oshimura M, Freeman AI, Sandberg AA. Chromosomes and causation of human cancer and leukemia XXIII. Nearhaploidy in acute leukemia. Cancer. 1977; 40:1143-1148.

14. Paulsson K, Johansson B. High hyperdiploid childhood acute lymphoblastic leukemia. Genes, Chromosomes \& Cancer. 2009; 48:637-660.

15. Holmfeldt L, Wei L, Diaz-Flores E, Walsh M, Zhang J, Ding L, Payne-Turner D, Churchman M, Andersson A, Chen SC, McCastlain K, Becksfort J, Ma J. The genomic landscape of hypodiploid acute lymphoblastic leukemia. Nature Genetics. 2013; 45:242-252.

16. Mühlbacher V, Zenger M, Schnittger S, Weissmann S, Kunze F, Kohlmann A, Bellos F, Kern W, Haferlach T, Haferlach C. Acute lymphoblastic leukemia with low hypodiploid/near triploid karyotype is a specific clinical entity and exhibits a very high TP53 mutation frequency of 93\%. Genes, Chromosomes \& Cancer. 2014; 53:524-536.

17. Safavi S, Hansson M, Karlsson K, Biloglav A, Johansson B, Paulsson K. Novel gene targets detected by genomic profiling in a consecutive series of 126 adults with acute lymphoblastic leukemia. Haematologica. 2015; 100:55-61.

18. Olsson L, Castor A, Behrendtz M, Biloglav A, Forestier E, Paulsson K, Johansson B. Deletions of IKZF1 and SPRED1 are associated with poor prognosis in a population-based series of pediatric B-cell precursor acute lymphoblastic leukemia diagnosed between 1992 and 2011. Leukemia. 2014; 28:302-310.

19. Li R, Li Y, Kristiansen K, Wang J. SOAP: short oligonucleotide alignment program. Bioinformatics. 2008; 24:713-714.

20. Gonzalez-Perez A, Lopez-Bigas N. Improving the assessment of the outcome of nonsynonymous SNVs with a consensus deleteriousness score, Condel. American Journal of Human Genetics. 2011; 88:440-449.

21. Cibulskis K, Lawrence MS, Carter SL, Sivachenko A, Jaffe D, Sougnez C, Gabriel S, Meyerson M, Lander ES, Getz G. Sensitive detection of somatic point mutations in impure and heterogeneous cancer samples. Nature Biotechnology. 2013; 31:213-219. 
22. Gentleman RC, Carey VJ, Bates DM, Bolstad B, Dettling M, Dudoit S, Ellis B, Gautier L, Ge Y, Gentry J, Hornik K, Hothorn T, Huber W. Bioconductor: open software development for computational biology and bioinformatics. Genome Biology. 2004; 5:R80.

23. Touleimat N, Tost J. Complete pipeline for Infinium((R)) Human Methylation 450K BeadChip data processing using subset quantile normalization for accurate DNA methylation estimation. Epigenomics. 2012; 4:325-341.

24. Mootha VK, Lindgren CM, Eriksson KF, Subramanian A, Sihag S, Lehar J, Puigserver P, Carlsson E, Ridderstråle M, Laurila E, Houstis N, Daly MJ, Patterson N. PGC-1alpharesponsive genes involved in oxidative phosphorylation are coordinately downregulated in human diabetes. Nature Genetics. 2003; 34:267-273.

25. Subramanian A, Tamayo P, Mootha VK, Mukherjee S, Ebert BL, Gillette MA, Paulovich A, Pomeroy SL, Golub TR, Lander ES, Mesirov JP. Gene set enrichment analysis: a knowledge-based approach for interpreting genome-wide expression profiles. Proceedings of the National Academy of Sciences of the United States of America. 2005; 102:15545-15550.
26. Paulsson K, Lilljebjorn H, Biloglav A, Olsson L, Rissler M, Castor A, Barbany G, Fogelstrand L, Nordgren A, Sjögren H, Fioretos T, Johansson B. The genomic landscape of high hyperdiploid childhood acute lymphoblastic leukemia. Nature Genetics. 2015; 47:672-676.

27. Mandahl N, Johansson B, Mertens F, Mitelman F. Diseaseassociated patterns of disomic chromosomes in hyperhaploid neoplasms. Genes, Chromosomes \& Cancer. 2012; 51:536-544.

28. Nord KH, Paulsson K, Veerla S, Wejde J, Brosjo O, Mandahl N, Mertens F. Retained heterodisomy is associated with high gene expression in hyperhaploid inflammatory leiomyosarcoma. Neoplasia. 2012; 14:807-812.

29. Swerdlow S, Campo E, Lee Harris N, Jaffe ES, Pileri SA, Stein H, Thiele J, Vardiman JW. WHO classification of tumours of haematopoietic and lymphoid tissues. IARC: Lyon 2008.

30. Paulsson K. Genomic heterogeneity in acute leukemia. Cytogenet Genome Res. 2013; 139:174-180. 